\title{
OPEN Monodisperse palladium-cobalt alloy nanocatalyst supported on activated carbon (AC) as highly effective catalyst for the DMAB dehydrocoupling
}

\begin{abstract}
Betul Sen ${ }^{1,2}$, Hilal Acidereli ${ }^{1,2}$, Neslihan Karaman ${ }^{1}$ \& Fatih Sen $\mathbb{1}^{1 凶}$
In the study, activated carbon (AC) supported palladium/cobalt (Pd/Co) nanocatalyst was synthesized to achieve hydrogen release from dimethylamine boron (DMAB). Nanocatalyst were produced by the reduction of $\mathrm{Pd}^{2+}$ and $\mathrm{Co}^{2+}$ cations by the ultrasonic double reduction method. Analytical studies of the synthesized nanomaterials were characterized by X-ray photoelectron spectroscopy, Raman spectroscopy, X-ray diffraction, transmission electron microscopy (TEM), high-resolution transmission electron microscopy (HR-TEM), electron energy loss spectroscopy, ultraviolet-visible spectroscopy. In this research, nanomaterials exhibited high catalytic activity and reusability, and great performance at low temperatures and concentrations. For the dehydrogenation reaction of dimethylamine borane, TOF and Ea were calculated as $379.5 \mathrm{~h}^{-1}$ and $75.86 \mathrm{~kJ} \mathrm{~mol}^{-1}$, respectively. The PdCo@AC nanocatalyst can be used as a promising catalyst for the hydrogen production reaction from DMAB.
\end{abstract}

Energy is considered a component of all activities and plays an important role in the economic development of any country. Increasing energy demand of the end users, one of the biggest problems of today, have been led researchers to investigate alternative, renewable and clean energy sources for energy supplying and storage. The use of hydrogen in countries with high energy dependence is widely involved in research and development. The hydrogen energy system is the best energy system expected to replace the fossil fuel system before the end of the twenty-first century. Hydrogen; in the next decades, is expected to become widespread use as an energy carrier for the supply of cheap electricity generation. However, easy production and improvement of storage are key points of the hydrogen economy for being safe, efficient and economical. Hydrogen energy is a high quality, non-polluting and, environmentally friendly. The state of art in the hydrogen economy are large and impressive. The creation of a worldwide energy network is essential for safe, economical transport ${ }^{1-4}$.

To date, metal complexes, metallic alloys, metal-organic frames (MOFs), and carbon materials have been studied as hydrogen storage materials. Metals such as $\mathrm{Pd}, \mathrm{Ru}, \mathrm{Pt}, \mathrm{Rh}$ have been investigated for hydrogen storage. Since Pd can absorb a thousand times its own volume of hydrogen at ambient temperature and pressure, it is one of the leading hydrogen storage material. Therefore, research on Pd hydride ( $\mathrm{Pd}-\mathrm{H})$ has been extensively studied in various fields, including hydrogen storage materials, purification filters, isotope separation membranes, and sensors. Such metals show high performance for hydrogen storage ${ }^{5,6}$. However, its high-cost is big a disadvantage. In order to reduce the cost, studies have been performed with low-cost metal nanocatalysts such as nickel $(\mathrm{Ni})$, copper $(\mathrm{Cu})$, iron $(\mathrm{Fe})$, and cobalt $(\mathrm{Co})$. When cost effective metals are used alone, catalyst showed low performance and reusability ${ }^{7-9}$. For this reason, it is aimed to synthesize both high activity and relatively cost effective catalyst by forming Co-Pd alloy. Activated carbon (AC) was used as a support to increase the active surface area of metal alloy and improve the catalytic performance. The AC support dimensionally stabilizes $\mathrm{Pd} /$ Co metal alloy and has great potential as hydrogen carriers.

${ }^{1}$ Sen Research Group, Biochemistry Department, Faculty of Arts and Science, Dumlupınar University, Evliya Celebi Campus, 43100 Kutahya, Turkey. ${ }^{2}$ These authors contributed equally: Betul Sen and Hilal Acidereli. ${ }^{\square}$ email: fatihsen1980@gmail.com 

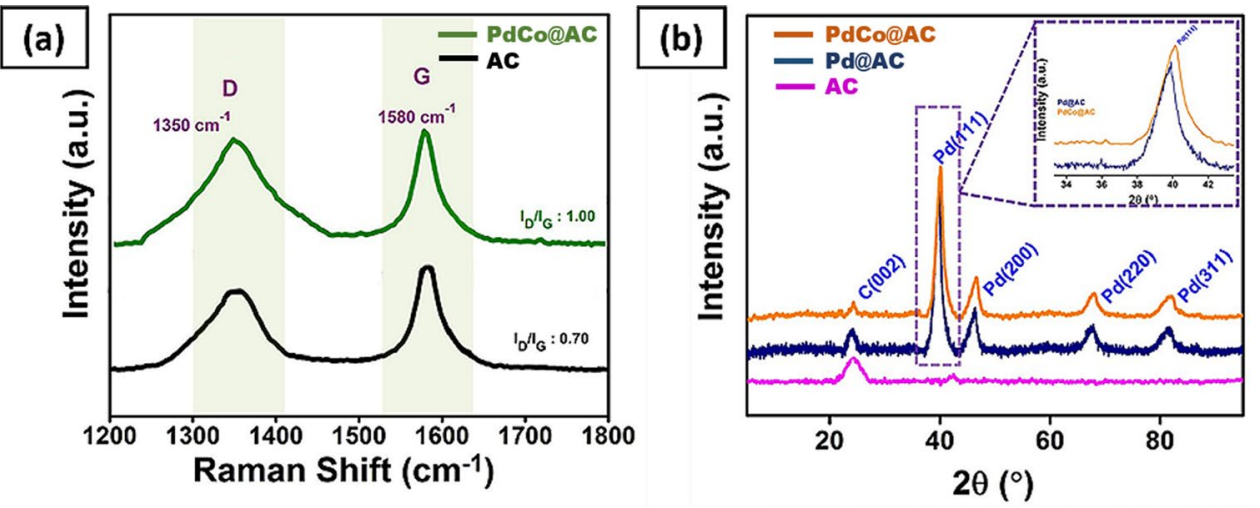

Figure 1. (a) Raman spectrum of AC and PdCo@AC; (b) XRD of AC, Pd@AC and PdCo@AC NPs.

The ammonia boranes $(\mathrm{AB})$ and its derivatives are a good source of hydrogen in the presence of a suitable catalyst and have a high hydrogen content. Under optimal conditions and suitable catalyst, hydrogen can be produced from the $\mathrm{ABs}^{10,11}$. Dimethylamine borane (DMAB) is an environmentally friendly, stable $\mathrm{AB}$ derivative. The disadvantage of dehydrogenation of $\mathrm{AB}$ is the long induction time before the start of hydrogen release ${ }^{12}$. Safe and efficient hydrogen storage is possible with new generation technologies. However, still there is a need to develop industrial-scale low-cost nanocatalysts for the dehydrogenation of the ABs and its derivatives and, transport is a problem due to the low hydrogen density. Therefore, the need for high-density chemicals to transport hydrogen has increased ${ }^{13,14}$. To this end, hydrazine $\left(\mathrm{N}_{2} \mathrm{H}_{4}\right)$, ammonia-borane $\left(\mathrm{NH}_{3} \mathrm{BH}_{3}\right)$, sodium borohydride $\left(\mathrm{NaBH}_{4}\right)$ are used ${ }^{15-18}$. Several different support materials and metals are important components in the composition of catalysts to obtain highly active and stable nanocatalyst. DMAB from AB derivatives is preferred because of its properties such as crystalline solid, stable in air and water, non-toxic. Compared to ABs, DMAB products are a good model substrate that is easy to maintain and control $^{19}$.

Equation (1) shows the catalytic reaction for the release of hydrogen from DMAB. When 1 mol of DMAB reacts, $1 \mathrm{~mol}$ of hydrogen gas is released. The reaction is conducted in room conditions (RT).

$$
\left.2\left(\mathrm{CH}_{3}\right)_{2} \mathrm{NHBH}_{3} \underset{\mathrm{RT}}{\stackrel{\text { Catalyst }}{\longrightarrow}}\left[\left(\mathrm{CH}_{3}\right)_{2} \mathrm{~N} \cdot \mathrm{BH}_{2}\right)\right]_{2}+2 \mathrm{H}_{2}
$$

Dimethylamine borane dehydrogenation reaction [ $\left.\mathrm{Cp}_{2} \mathrm{Ti}\right], \mathrm{Rh} 4-6$ clusters, $\mathrm{RhCl}_{3}$, colloidal Rh/[Oct $\left.{ }_{4} \mathrm{~N}\right) \mathrm{Cl}$, iridium, palladium, rhodium, ruthenium complexes, $\mathrm{Rh} / \mathrm{Al}_{2} \mathrm{O}_{3}, \mathrm{Pt}(0) /$ amyl amine, laurate-stabilized $\mathrm{Rh}(0), \mathrm{Re}$ complexes, Ru/ZIF-8, Pd (0)/MOF catalysts were tested ${ }^{19-28}$. Synthesis and characterization of palladium/cobalt nanomaterials stabilized with activated carbon on the release of hydrogen from DMAB were performed. The Pd/ Co metal was reduced together using the ultrasonic double reduction method. The activated carbon used as a support material in the synthesized catalyst is a carbonaceous material with a well-developed porous structure and large surface area. This is to give the activated carbon a strong adsorption property. The structure of the PdCo@AC nanomaterial was characterized by XPS, XRD, Raman, TEM, and HRTEM.

\section{Materials and methods}

Synthesis of activated carbon stabilized palladium/cobalt nanocatalyst. In this research, PdCo@ AC nanocatalyst was successfully synthesized by the ultrasonic double reduction method ${ }^{29} .0 .25 \mathrm{mmol}$ of $\mathrm{CoCl}_{2}$ and $0.25 \mathrm{mmol}$ of $\mathrm{PdCl}_{2}$ were stirred under ultrasonic conditions by adding $15 \mathrm{~mL}$ tetrahydrofuran (THF) and $2.5 \mathrm{mmol}$ of activated carbon was added. The mixture was refluxed for two hours at $90^{\circ} \mathrm{C}$. The catalyst was synthesized using the $\mathrm{Pd} / \mathrm{Co}$ nanocatalyst support material activated carbon to form a blackish solid material. The formation of black color is indicative of a stable nanocatalyst. Activated carbon was used as a support material. Stability, reusability catalytic performances of PdCo@AC nanocatalyst synthesized for DMAB dehydrogenation reaction were investigated. The experiments were performed in three parallel, and data presented in graphics is average of triplicated data. Error bars represented standard deviation (SD). Materials and equipment used are given in Supporting Information.

\section{Results and discussions}

Synthesis and analytical characterization of PdCo@AC nanocatalyst. In this study, for carbonaceous materials were identified by the Raman spectroscopy. The Raman spectrum of PdCo@AC nanocatalyst and activated carbon is shown in Fig. 1a. In Raman spectroscopy, the scattering peaks were detected $1,350.6 \mathrm{~cm}^{-1}$ and $1,580.8 \mathrm{~cm}^{-1}$. The $\mathrm{I}_{\mathrm{D}} / \mathrm{I}_{\mathrm{G}}$ ratio can be used for the degree of modification in AC. $\mathrm{I}_{\mathrm{D}} / \mathrm{I}_{\mathrm{G}}$ ratios of $\mathrm{AC}$ and PdCo@ $\mathrm{AC}$ nanocatalyst were calculated as 0.70 and 1.00 , respectively, indicating that the activated carbon (AC) lattice deteriorated after functionalization by palladium and cobalt metals. 

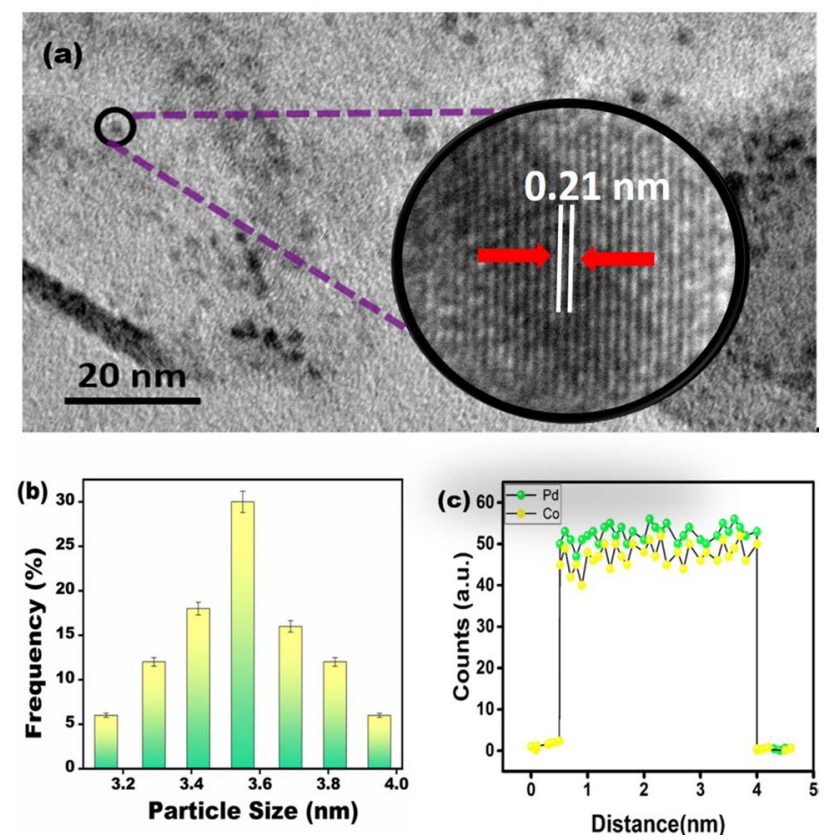

Figure 2. (a) TEM and HR-TEM image, (b) particle size histogram, (c) the EELS line profile of the Pd/Co nanocatalyst.

XRD technique was performed to identify the crystal structure and average crystallite size of PdCo@AC nanocatalyst. In Fig. $1 \mathrm{~b}$, the peaks at $2 \theta=40.2^{\circ}, 48.6^{\circ}, 71.7^{\circ}$, and $86.6^{\circ}$ corresponding to the crystal planes of Pd (111), (200), (220) and (311), respectively, that indicate face-centered cubic structure. Moreover, diffraction peaks shifted slightly to higher $2 \theta$ values compared to pure palladium. This indicates the alloy formation of PdCo@ AC nanocatalyst. Here, around $24.9^{\circ}$ peak is related to activated carbon. In the X-ray powder diffraction models for $\mathrm{Pd} / \mathrm{Co}$, the diffraction peaks of the cobalt species were not significant due to the strong signals for the palladium species associated with the amorphous structure of the materials. The crystalline size was calculated as $3.71 \pm 0.43 \mathrm{~nm}$ using Eq. $(2)^{30}$.

$$
d(\AA)=\frac{k \lambda}{\beta \cos \theta}
$$

where $\lambda$ is the wavelength of the X-ray used (1.54056 $\AA$ ), k coefficient (0.9), $\beta$ is the full width of the half-width of the respective diffraction peak in rad radiation, and $\theta$ is the maximum peak in rad position.

The lattice parameter was calculated using Pd (220) diffraction peak. The lattice parameter value for PdCo@ AC nanocatalyst was calculated as $3.88 \AA$ using Eq. (3). This result is in line with the pure palladium value $(3.89 \AA)^{21,31,32}$.

$$
\operatorname{Sin} \theta=\frac{\lambda \sqrt{h^{2}+k^{2}+l^{2}}}{2 a}
$$

According to the UV-VIS results, as shown in SI Fig. S1, the conversion of the palladium and cobalt material to the $\mathrm{Pd} / \mathrm{Co}$ nanomaterials with the activated carbon support material is large and the absorption lines indicating that the cations at the reflux end are reduced due to transitions of $\mathrm{d}-\mathrm{d}$ disappeared.

In Fig. 2, the morphology, composition and particle size of PdCo@AC nanocatalyst were determined by TEM-ELLS analyses. The HR-TEM results showing the morphology of the nanomaterial are shown in Fig. $2 \mathrm{a}$. Particle size of $3.55 \pm 0.40 \mathrm{~nm}$ was measured as shown in Fig. $2 \mathrm{~b}$. The particles were spherical and there was no agglomeration. In the HRTEM image, atomic lattice fringes of PdCo@AC nanocatalyst were also observed. The atomic lattice fringe of $\mathrm{Pd}$ (111) plane was determined as $0.21 \mathrm{~nm}$ which is smaller than the nominal Pd (111) range $(0.22 \mathrm{~nm})^{12,32-34}$. This result indicates that particle size is reduced by formation of Pd-Co alloy. Figure $2 \mathrm{c}$ shows the EELS line profile of the Pd-Co nanoparticles. Accordingly, Pd and Co forming an alloy of about 1:1.

Surface composition and chemical oxidation states of palladium and cobalt in PdCo@AC nanocatalyst were investigated by XPS analytical method. The spectra of Pd (3d) and Co (2p) regions were determined by the Gaussian-Lorentz method. In the X-ray photoelectron spectroscopy spectrum, the binding energies were determined with reference to the $284.1 \mathrm{eV} \mathrm{C1s} \mathrm{peak.} \mathrm{The} \mathrm{XPS} \mathrm{spectrum,} \mathrm{metallic} \mathrm{Pd} \mathrm{(0)} \mathrm{peaks} \mathrm{were} \mathrm{seen} \mathrm{at} 335.7 \mathrm{eV}$ and $341.0 \mathrm{eV}$ and $\mathrm{Pd}$ (II) peaks were detected at $337.5 \mathrm{eV}$ and $343.0 \mathrm{eV}$ (Fig. 3a). Co (0) peaks were seen at $781.6 \mathrm{eV}$ 

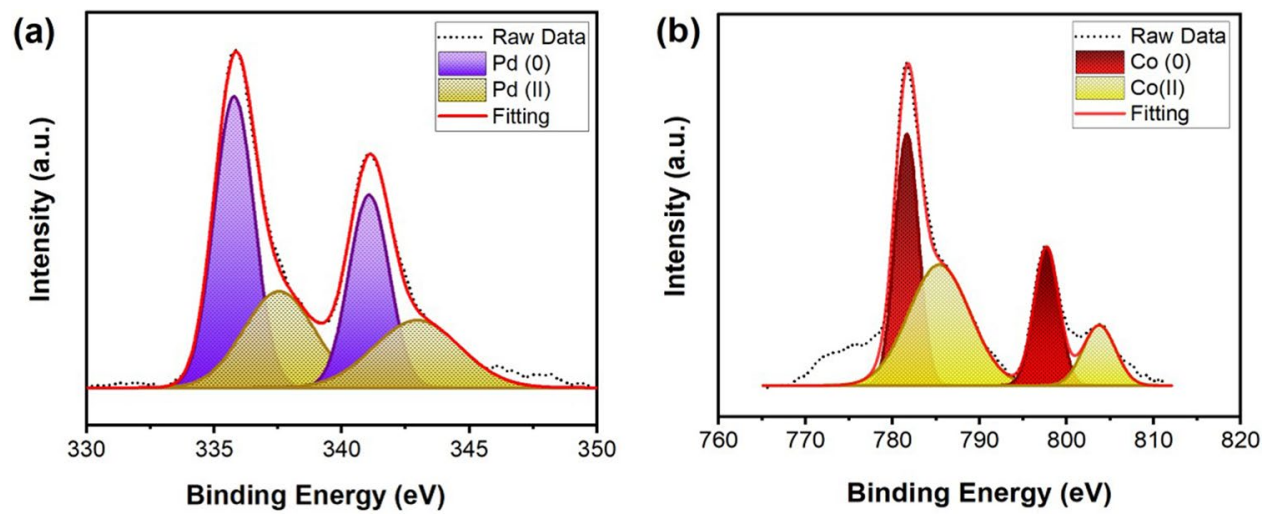

Figure 3. (a) Palladium 3d (b) Cobalt 2p XPS spectra of PdCo@AC nanocatalyst.

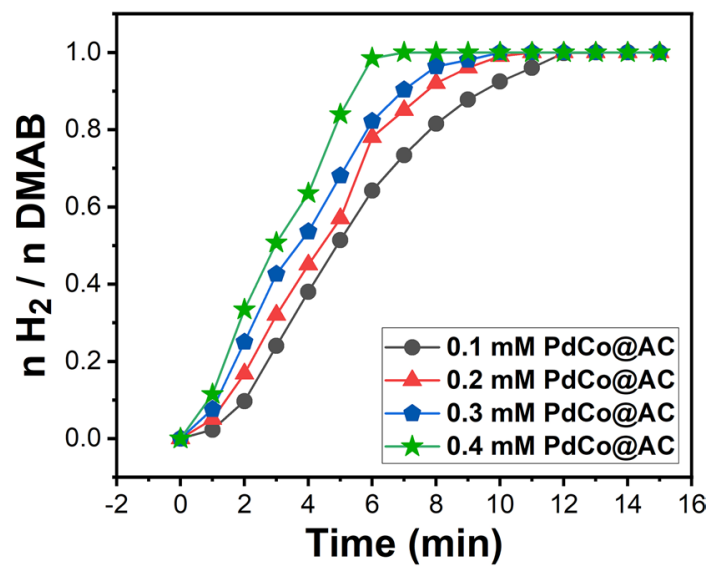

Figure 4. (a) Plot $\mathrm{nH}_{2} / \mathrm{nDMAB}$ versus time for dehydrogenation of $\mathrm{DMAB}$ in the presence of PdCo@AC nanocatalyst at different concentrations at $25.0 \pm 0.1^{\circ} \mathrm{C}$.

and $797.6 \mathrm{eV}$ and $\mathrm{Co}$ (II) peaks were detected at $785.4 \mathrm{eV}$ and $803.7 \mathrm{eV}$ (Fig. 3b). Comparison of peak intensities revealed that $\mathrm{Pd}$ and Co are mostly in metallic form. The low amount of oxidation peaks due to the fact that oxidation of environmental oxygen may result chemical absorption on the surface.

During the catalytic dehydrogenation reaction of DMAB, it was observed that metal composites of palladium and cobalt nanocatalyst were physically mixed (1:1) and Pd/Co bimetallic nanocatalyst (1:1) was synthesized successfully.PdCo@AC nanocatalyst has higher catalytic performance than pure palladium and cobalt mixtures due to the synergetic effect of each component. NMR analysis results for $\left(\mathrm{CH}_{3}\right)_{2} \mathrm{NHBH}_{3}$ are given in Supporting Information.

Investigation of the performance of palladium/cobalt nanomaterials stabilized with activated carbon support. In this research, the PdCo@AC nanocatalyst can be used as high-efficiency catalysts on the release of hydrogen from dimethylamine borane. The $\mathrm{nH}_{2} / \mathrm{nDMAB}$ plot versus time is shown at $25.0 \pm 0.10^{\circ} \mathrm{C}$ at different concentrations of $0.1 \mathrm{mM}, 0.2 \mathrm{mM}, 0.3 \mathrm{mM}$ and $0.4 \mathrm{mM}$ in Fig. 4a for the dehydrogenation reaction of dimethylamine borane. The release of hydrogen starts timely, induction linearly and rapidly, and continues until the release of hydrogen from dimethylamine borane ends.

Hydrogen production rate constants at different temperatures are determined and plotted in Fig. 5. Arrhenius and Eyring plots were drawn with the help of Fig. 5, and the TOF, Ea, $\Delta \mathrm{H}$, and $\Delta \mathrm{S}$ values were calculated. Figure 6a shows the activation energy that calculated as $75.86 \mathrm{~kJ} \mathrm{~mol}^{-1}$ using Arrhenius plot rate constants. With the help of Fig. $6 \mathrm{~b}, \Delta \mathrm{H}$ and $\Delta \mathrm{S}$ were calculated as $73.36 \mathrm{~kJ} \mathrm{~mol}^{-1}$ and $-12.37 \mathrm{~J} \mathrm{~mol}^{-1} \mathrm{~K}^{-1}$, respectively. The percent conversion calculated after the three parallel experiments were given in the Supporting Information.

TOF value of the PdCo@AC nanocatalyst was calculated as $379.5 \mathrm{~h}^{-1}$. TOF value $\left(379.5 \mathrm{~h}^{-1}\right)$ is one of the highest values in the literature. Table 1 summarizes that some different nanocatalysts were tested for hydrogen production from DMAB. As shown in Table 1, some bimetallic catalysts exhibited high catalytic performance 


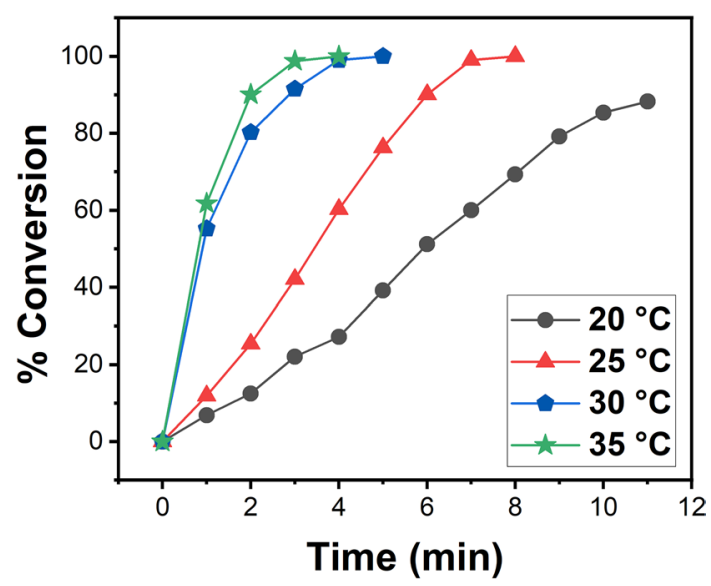

Figure 5. Plot of conversion percentage versus time for DMAB ( $150 \mathrm{mM}$ in $15 \mathrm{~mL}$ THF) beginning with PdCo@AC NPs ([PdCo@AC NPs] 7.5 mol \% in THF) at varied temperatures within $20-35^{\circ} \mathrm{C}$ range.
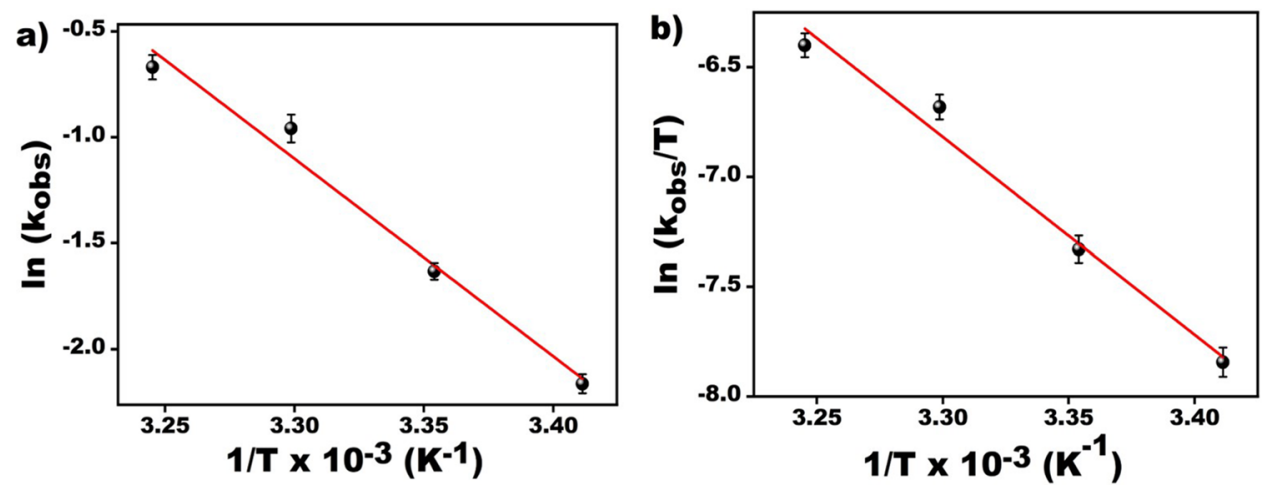

Figure 6. (a) Arrhenius and (b) eyring plots for the PdCo@AC nanocatalyst dehydrogenation of DMAB at various temperatures.

and TOF values in the same reaction. The result showed that PdCo@AC nanocatalyst can be used effectively in catalytic dehydrogenation reactions due to its efficiency, stability and reusability.

The cyclic property of activated carbon-supported $\mathrm{Pd} /$ Co nanocatalyst was investigated. As shown in SI Fig. S2, the PdCo@AC nanocatalyst retained about 80\% of initial performance after the 7th cycle. The diminution of catalytic activity in the dimethylamine borane dehydrogenation reaction is due to the increased amount of nanocatalyst on the surfaces of the nanocatalyst, which may result in passivation and therefore reduced active site accessibility.

\section{Conclusions}

- The active carbon-supported Pd/Co nanomaterials upon hydrogen release from dimethylamine borane were synthesized as an effective nanocatalyst PdCo@AC by ultrasonic double reduction.

- Synthesized PdCo@AC nanocatalyst exhibited very good catalytic performance compared to literature data for dehydrogenation of DMAB.

- The TOF value was found to be $379.5 \mathrm{~h}^{-1}$ on the hydrogen release reaction from DMAB.

- Activation energy, $\Delta \mathrm{H}$, and $\Delta \mathrm{S}$ in the presence of PdCo@AC nanocatalyst were calculated as $75.86 \mathrm{~kJ} \mathrm{~mol}^{-1}$, $73.36 \mathrm{~kJ} \mathrm{~mol}^{-1}$, and $-12.37 \mathrm{~J} \mathrm{~mol}^{-1} \mathrm{~K}^{-1}$, respectively.

- Results showed that PdCo@AC nanocatalyst is promising nanomaterials for the dehydrogenation of DMAB and can be utilized for the hydrogen energy applications. 


\begin{tabular}{|c|c|c|c|}
\hline Catalysts & TOF $\left(h^{-1}\right)$ & Conversion (\%) & References \\
\hline PdCo@AC & 379.5 & 100 & This study \\
\hline $\mathrm{Ru}(\operatorname{cod})(\cot )$ & 1.6 & 40 & 28 \\
\hline $\mathrm{Cp}_{2} \mathrm{Ti}$ & 12.3 & 100 & 35 \\
\hline$\left[\mathrm{Rh}(1,5-\operatorname{cod})_{2}\right] \mathrm{Otf}$ & 12.0 & 95 & 36 \\
\hline$\left[\mathrm{RhCl}\left(\mathrm{PHCy}_{2}\right)_{3}\right]$ & 2.6 & 100 & 22 \\
\hline$\left[\mathrm{Cr}(\mathrm{CO})_{5}(\mathrm{thf})\right]$ & 13.4 & 97 & 21 \\
\hline$\left[\mathrm{Cp}^{*} \mathrm{Rh}(\mathrm{m}-\mathrm{Cl}) \mathrm{Cl}\right]_{2}$ & 0.9 & 100 & 37 \\
\hline PdCo@PVP & 330 & 100 & 32 \\
\hline $\mathrm{HRh}(\mathrm{CO})\left(\mathrm{PPh}_{3}\right)_{3}$ & 0.1 & 5 & 38 \\
\hline $\mathrm{RuCl}_{3} \cdot 3 \mathrm{H}_{2} \mathrm{O}$ & 2.7 & 77 & 35 \\
\hline trans- $\mathrm{RuMe}_{2}\left(\mathrm{PMe}_{3}\right)_{4}$ & 12.4 & 100 & 36 \\
\hline$[\mathrm{Rh}(1,5 \text {-cod }) \mathrm{m}-\mathrm{Cl}]_{2}$ & 12.5 & 100 & 36 \\
\hline$\left[\mathrm{Ru}(1,5-\mathrm{cod}) \mathrm{Cl}_{2}\right] \mathrm{n}$ & 2.5 & 70 & 35 \\
\hline $\mathrm{Pt}(0) / \mathrm{TBA}$ & 31.24 & 100 & 39 \\
\hline $\mathrm{RhCl}\left(\mathrm{PPh}_{3}\right)_{3}$ & 4.3 & 100 & 36 \\
\hline $\mathrm{IrCl}_{3}$ & 0.3 & 25 & 38 \\
\hline $\mathrm{Pd} / \mathrm{C}$ & 2.8 & 95 & 40 \\
\hline $\mathrm{RhCl}_{3}$ & 7.9 & 90 & 41 \\
\hline$\left[\mathrm{Cr}(\mathrm{CO})_{5}\left(\eta 1-\mathrm{BH}_{3} \mathrm{NMe}_{3}\right)\right]$ & 19.9 & 97 & 21 \\
\hline$\left[\mathrm{RuH}\left(\mathrm{PMe}_{3}\right)\left(\mathrm{NC}_{2} \mathrm{H}_{4} \mathrm{PPr}_{2}\right)_{2}\right]$ & 1.5 & 100 & 38 \\
\hline $\mathrm{Ni}($ skeletal) & 3.2 & 100 & 23 \\
\hline$[\mathrm{Ir}(1,5-\mathrm{cod}) \mathrm{m}-\mathrm{Cl}]_{2}$ & 0.7 & 95 & 42 \\
\hline Pt(0)/TPA@AC & 34.14 & 100 & 39 \\
\hline$[\mathrm{Rh}(1,5-\operatorname{cod})(\mathrm{dmpe})] \mathrm{PF}_{6}$ & 1.7 & 95 & 40 \\
\hline (Idipp)CuCl & 0.3 & 100 & 43 \\
\hline $\mathrm{Rh}(0) \mathrm{NPs}$ & 60.0 & 100 & 44 \\
\hline
\end{tabular}

Table 1. TOF values of catalysts for dimethylamine borane dehydrogenation.

Received: 4 February 2020; Accepted: 2 July 2020

Published online: 16 July 2020

\section{References}

1. Guo, S. et al. High-performance symmetric sodium-ion batteries using a new, bipolar O3-type material, $\mathrm{Na}_{0.8} \mathrm{Ni}_{0.4} \mathrm{Ti}_{0.6} \mathrm{O}_{2}$. Energy Environ. Sci. 8, 1237-1244 (2015).

2. Andrews, J. \& Shabani, B. Re-envisioning the role of hydrogen in a sustainable energy economy. Int. J. Hydrogen Energy 37, 1184-1203 (2012).

3. Demirkan, B. et al. Composites of bimetallic platinum-cobalt alloy nanoparticles and reduced graphene oxide for electrochemical determination of ascorbic acid, dopamine, and uric acid. Sci. Rep. 9, 12258 (2019).

4. Diler, F. et al. Efficient preparation and application of monodisperse palladium loaded graphene oxide as a reusable and effective heterogeneous catalyst for suzuki cross-coupling reaction. J. Mol. Liq. https://doi.org/10.1016/j.molliq.2019.111967 (2019).

5. Brodowsky, H. The palladium hydrogen system . Von F. A. Lewis, Academic Press, London-New York 1967. 1. Aufl., XII, 178 S., zahlr. Abb., geb. 45 s. Angew. Chem. https://doi.org/10.1002/ange.19680801227 (1968).

6. Kirchheim, R. \& Pundt, A. Hydrogen in metals. Phys. Metall. https://doi.org/10.1016/B978-0-444-53770-6.00025-3 (2014).

7. Du, Y., Cao, N., Yang, L., Luo, W. \& Cheng, G. One-step synthesis of magnetically recyclable rGO supported Cu@Co core-shell nanoparticles: Highly efficient catalysts for hydrolytic dehydrogenation of ammonia borane and methylamine borane. New J. Chem. https://doi.org/10.1039/c3nj00552f (2013).

8. Yang, L., Luo, W. \& Cheng, G. Graphene-supported Ag-based core-shell nanoparticles for hydrogen generation in hydrolysis of ammonia borane and methylamine borane. ACS Appl. Mater. Interfaces https://doi.org/10.1021/am402373p (2013).

9. Baguc, I. B. et al. Nanocrystalline metal organic framework (MIL-101) stabilized copper nanoparticles: Highly efficient nanocatalyst for the hydrolytic dehydrogenation of methylamine borane. Inorg. Chim. Acta 483, 431-439 (2018).

10. Sogut, E. G. et al. Single-walled carbon nanotube supported Pt-Ru bimetallic superb nanocatalyst for the hydrogen generation from the methanolysis of methylamine-borane at mild conditions. Sci. Rep. 9, 15724 (2019).

11. Karatas, Y., Kuyuldar, E., Acidereli, H., Gulcan, M. \& Sen, F. Polypyrrole-multi walled carbon nanotube hybrid material supported Pt NPs for hydrogen evolution from the hydrolysis of MeAB at mild conditions. Sci. Rep. 9, 18553 (2019).

12. Staubitz, A., Robertson, A. P. M. \& Manners, I. Ammonia-borane and related compounds as dihydrogen sources. Chem. Rev. 110, 4079-4124 (2010).

13. Rossin, A. \& Peruzzini, M. Ammonia-borane and amine-borane dehydrogenation mediated by complex metal hydrides. Chem. Rev. 116, 8848-8872 (2016).

14. Robertson, A. P. M., Suter, R., Chabanne, L., Whittell, G. R. \& Manners, I. Heterogeneous dehydrocoupling of amine-borane adducts by skeletal nickel catalysts. Inorg. Chem. 50, 12680-12691 (2011).

15. Sun, W. et al. Hydrazine bisborane as a promising material for chemical hydrogen storage. Int. J. Hydrogen Energy 36, 13640-13644 (2011). 
16. Yousef, A., Barakat, N. A. M., EL-Newehy, M. H., Ahmed, M. M. \& Kim, H. Catalytic hydrolysis of ammonia borane for hydrogen generation using $\mathrm{Cu}(0)$ nanoparticles supported on $\mathrm{TiO}_{2}$ nanofibers. Colloids Surf. A Physicochem. Eng. Asp. https://doi. org/10.1016/j.colsurfa.2015.02.004 (2015).

17. Brack, P., Dann, S. E. \& Wijayantha, K. G. U. Heterogeneous and homogenous catalysts for hydrogen generation by hydrolysis of aqueous sodium borohydride $\left(\mathrm{NaBH}_{4}\right)$ solutions. Energy Sci. Eng. 3, 174-188 (2015).

18. Yu, L. \& Matthews, M. A. A reactor model for hydrogen generation from sodium borohydride and water vapor. Int. J. Hydrogen Energy 39, 3830-3836 (2014).

19. Jiang, Y. \& Berke, H. Dehydrocoupling of dimethylamine-borane catalysed by rhenium complexes and its application in olefin transfer-hydrogenations. Chem. Commun. 20, 3571-3573. https://doi.org/10.1039/b708913a (2007).

20. Clark, T. J., Russell, C. A. \& Manners, I. Homogeneous, titanocene-catalyzed dehydrocoupling of amine-borane adducts. J. Am. Chem. Soc. 128, 9582-9583 (2006).

21. Sloan, M. E. et al. Homogeneous catalytic dehydrocoupling/dehydrogenation of amine-borane adducts by early transition metal, Group 4 metallocene complexes. J. Am. Chem. Soc. 132, 3831-3841 (2010).

22. Fulton, J. L. et al. When is a nanoparticle a cluster? An operando EXAFS study of amine borane dehydrocoupling by Rh4-6clusters. J. Am. Chem. Soc. https://doi.org/10.1021/ja0733311 (2007).

23. Jaska, C. A., Temple, K., Lough, A. J. \& Manners, I. Transition metal-catalyzed formation of boron-nitrogen bonds: Catalytic dehydrocoupling of amine-borane adducts to form aminoboranes and borazines. J. Am. Chem. Soc. https://doi.org/10.1021/ja030 1601 (2003).

24. Jaska, C. A. \& Manners, I. Heterogeneous or homogeneous catalysis? Mechanistic studies of the rhodium-catalyzed dehydrocoupling of amine-borane and phosphine-borane adducts. J. Am. Chem. Soc. https://doi.org/10.1021/ja0478431 (2004).

25. Sen, F., Karatas, Y., Gulcan, M. \& Zahmakiran, M. Amylamine stabilized platinum(0) nanoparticles: Active and reusable nanocatalyst in the room temperature dehydrogenation of dimethylamine-borane. RSC Adv. 4, 1526-1531 (2014).

26. Durap, F., Zahmakıran, M. \& Özkar, S. Water soluble laurate-stabilized rhodium(0) nanoclusters catalyst with unprecedented catalytic lifetime in the hydrolytic dehydrogenation of ammonia-borane. Appl. Catal. A Gen. 369, 53-59 (2009).

27. Zhang, Q., Smith, G. M. \& Wu, Y. Catalytic hydrolysis of sodium borohydride in an integrated reactor for hydrogen generation. Int. J. Hydrogen Energy 32, 4731-4735 (2007).

28. Muñoz-Olasagasti, M., Telleria, A., Pérez-Miqueo, J., Garralda, M. A. \& Freixa, Z. A readily accessible ruthenium catalyst for the solvolytic dehydrogenation of amine-borane adducts. Dalt. Trans. 43, 11404 (2014).

29. Sen, B. et al. Monodisperse ruthenium-copper alloy nanoparticles decorated on reduced graphene oxide for dehydrogenation of DMAB. Int. J. Hydrogen Energy https://doi.org/10.1016/j.ijhydene.2019.02.176 (2019).

30. Liu, J. et al. Electro-oxidation of methanol, 1-propanol and 2-propanol on Pt and Pd in alkaline medium. J. Power Sources 177, 67-70 (2008).

31. Alcaraz, G., Grellier, M. \& Sabo-Etienne, S. Bis $\sigma$-bond dihydrogen and borane ruthenium complexes: Bonding nature, catalytic applications, and reversible hydrogen release. Acc. Chem. Res. 42, 1640-1649 (2009).

32. Çelik, B. et al. Monodispersed palladium-cobalt alloy nanoparticles assembled on poly(N-vinyl-pyrrolidone) (PVP) as a highly effective catalyst for dimethylamine borane (DMAB) dehydrocoupling. RSC Adv. 6, 24097-24102 (2016).

33. Jaska, C. A. et al. Transition metal-catalyzed formation of boron-nitrogen bonds: Catalytic dehydrocoupling of amine-borane adducts to form aminoboranes and borazines. J. Am. Chem. Soc. 125, 9424-9434 (2003).

34. Chen, Y., Fulton, J., Linehan, J. \& Autrey, T. In-situ spectroscopic studies of rhodium catalyzed production of hydrogen from dimethylamine borane. Homogeneous or heterogeneous catalysis?. ACS Div. Fuel Chem. 20, 972-973 (2004).

35. Zahmakıran, M. et al. Aminopropyltriethoxysilane stabilized ruthenium $(0)$ nanoclusters as an isolable and reusable heterogeneous catalyst for the dehydrogenation of dimethylamine-borane. Chem. Commun. 46, 2938 (2010).

36. Chen, Y., Fulton, J. L., Linehan, J. \& Autrey, T. In-situ spectroscopic studies of rhodium catalyzed production of hydrogen from dimethylamine borane: Homogeneous or heterogeneous catalysis? (2004).

37. Erken, E. et al. New $\mathrm{Pt}(0)$ Nanoparticles as Highly Active and Reusable Catalysts in the $\mathrm{C} 1-\mathrm{C} 3$ Alcohol Oxidation and the Room Temperature Dehydrocoupling of Dimethylamine-Borane (DMAB). J. Clust. Sci. 27, 9-23 (2016).

38. Chen, Y., Fulton, J. L., Linehan, J. C. \& Autrey, T. In situ XAFS and NMR study of rhodium-catalyzed dehydrogenation of dimethylamine borane. J. Am. Chem. Soc. https://doi.org/10.1021/ja0437050 (2005).

39. Sen, F., Karatas, Y., Gulcan, M. \& Zahmakiran, M. Amylamine stabilized platinum(0) nanoparticles: Active and reusable nanocatalyst in the room temperature dehydrogenation of dimethylamine-borane. RSC Adv. 4, 1526-1531 (2014).

40. Sen, B. et al. Composites of platinum-iridium alloy nanoparticles and graphene oxide for the dimethyl amine borane (DMAB) dehydrogenation at ambient conditions: An experimental and density functional theory study. Sci. Rep. 9, 20 (2019).

41. Zahmakiran, M. \& Özkar, S. Dimethylammonium hexanoate stabilized rhodium(0) nanoclusters identified as true heterogeneous catalysts with the highest observed activity in the dehydrogenation of dimethylamine-borane. Inorg. Chem. 48, 8955-8964 (2009).

42. Sen, B., Kuzu, S., Demir, E., Yıldırır, E. \& Sen, F. Highly efficient catalytic dehydrogenation of dimethyl ammonia borane via monodisperse palladium-nickel alloy nanoparticles assembled on PEDOT. Int. J. Hydrogen Energy 42, 23307-23314 (2017).

43. Shabnam, L. et al. Doped graphene/Cu nanocomposite: A high sensitivity non-enzymatic glucose sensor for food. Food Chem. 221, 751-759 (2017).

44. Ali, M. E., Rahman, M. M., Sarkar, S. M. \& Hamid, S. B. A. Heterogeneous metal catalysts for oxidation reactions. J. Nanomater. https://doi.org/10.1155/2014/192038 (2014).

\section{Acknowledgements}

H.A. would like to thank Turkish Council of Higher Education (YÖK) 100/2000 National PhD Fellowship Programme.

\section{Author contributions}

F.S. organized all experiments and wrote the manuscript B.S., H.A., and N.K. performed all experiments and characterizations. They have also drawn the figures.

\section{Competing interests}

The authors declare no competing interests.

\section{Additional information}

Supplementary information is available for this paper at https://doi.org/10.1038/s41598-020-68773-x.

Correspondence and requests for materials should be addressed to F.S.

Reprints and permissions information is available at www.nature.com/reprints. 
Publisher's note Springer Nature remains neutral with regard to jurisdictional claims in published maps and institutional affiliations.

(c) (i) Open Access This article is licensed under a Creative Commons Attribution 4.0 International License, which permits use, sharing, adaptation, distribution and reproduction in any medium or format, as long as you give appropriate credit to the original author(s) and the source, provide a link to the Creative Commons license, and indicate if changes were made. The images or other third party material in this article are included in the article's Creative Commons license, unless indicated otherwise in a credit line to the material. If material is not included in the article's Creative Commons license and your intended use is not permitted by statutory regulation or exceeds the permitted use, you will need to obtain permission directly from the copyright holder. To view a copy of this license, visit http://creativecommons.org/licenses/by/4.0/.

(c) The Author(s) 2020 